\title{
Anti-ErbB3 Monoclonal Antibody REGN1400
}

National Cancer Institute

\section{Source}

National Cancer Institute. Anti-ErbB3 Monoclonal Antibody REGN1400. NCI Thesaurus.

Code C103859.

A human monoclonal antibody directed against the human epidermal growth factor receptor ErbB3 (Her3) with potential antineoplastic activity. Upon administration, antiErbB3 monoclonal antibody REGN1400 binds to ErbB3 and prevents neuregulin 1 ligand binding to ErbB3, which may result in an inhibition of ErbB3-dependent phosphatidylinositol-3 kinase (PI3K)/Akt signaling. This eventually leads to the inhibition of cellular proliferation and differentiation. ErbB3, a member of the epidermal growth factor receptor (EGFR) family of receptor tyrosine kinases, is frequently overexpressed in a variety of solid tumors and its overexpression generally correlates with poor prognosis and tumor resistance. 